\title{
LA REVISTA ZaNAN, DE LA IRANí SHAHLA SHERKAT, Y SU CONTRIBUCión \\ AL FEMINISMO ISLÁMICO
}

\author{
Rocío Velasco de Castro \\ rvelde@unex.es \\ Universidad de Extremadura
}

Recibido: 13-12-2011

Aceptado: 14-03-2012

\section{Resumen}

En cualquier sociedad, el feminismo conforma una parte importante de la lucha por los derechos humanos. En las sociedades islámicas, además, muchas de las militantes feministas lideran los movimientos ciudadanos y sus demandas de libertad. En este proceso, la palabra como medio de expresión y de denuncia, constituye un eficaz y peligroso instrumento para informar y concienciar a la población. Al igual que otras periodistas y escritoras perseguidas, el testimonio de Sherkat y de su revista, Zanan, están considerados como uno de los principales portavoces no sólo del feminismo islámico en el país, sino también de la libertad de expresión cercenada por un régimen político dictatorial.

Palabras clave: Historia de las mujeres, feminismo islámico, Irán, prensa feminista, Zanan, Shahla Sherkat.

\begin{abstract}
In any society, feminism is an important part of the struggle for human rights. Furthermore, in Islamic societies, many of feminist activists lead the citizen movements as well as their requirements of freedom. In this process, the word as means of expression and denunciation becomes an effective but dangerous instrument to inform and make the people aware. As other journalists and writers who have been persecuted, tehn testimony of Sherkat and her magazine Zanan are considered not just as one of the main voices of Islamic feminism in the country, but also as a symbol of freedom of speech cut off by a dictatorial political regime.
\end{abstract}

Keywords: Women's history, Islamic feminism, Iran, feminist press, Zanan, Shahla Sherkat. 


\section{Introducción}

En este artículo, concebido como contribución a esbozar una panorámica de la presencia y visibilización de las feministas iraníes en la vida política, social y cultural del Irán actual, centraremos nuestra atención al activismo que, dentro del ámbito periodístico, desempeñan tres destacadas mujeres: Faezeh Hashemi Rafsanjani, Parvin Ardalán, y muy especialmente, Shahla Sherkat.

La participación de las mujeres iraníes en los media y su compromiso con la causa feminista resulta patente en representantes del mundo de la política que, habiendo comenzado su militancia dentro del movimiento estudiantil, realizaron incursiones en la prensa escrita (Zahra Rahnavard ${ }^{1}$ ), así como en activistas de los derechos humanos que defienden ante los tribunales a compañeras periodistas (Shirin Ebadi). Esta vinculación alcanza continuidad con las trayectorias de Faezeh Rafsanjani y Azam Taleghani, ambas políticas y periodistas, mientras que en el caso de Parvin Ardalán y Shahla Sherkat se circunscriben al ámbito de los medios de comunicación y los movimientos civiles. Asimismo, y desde el punto de vista ideológico, Ardalán se enmarcaría dentro del feminismo laicizante, mientras que Rafsanjani y Sherkat se adscribirían al feminismo islámico.

\section{El activismo de la prensa dirigida por mujeres}

El ejercicio del periodismo en sus distintos formatos, y más concretamente la llamada prensa feminista, constituye uno de los principales medios desde donde se está actuando con mayor ímpetu para cambiar una legislación discriminatoria (Merinero, 2001). Buena parte de la fuerza de estas publicaciones reside en la implicación del colectivo femenino, que en ambos grupos conforman un numeroso porcentaje, ya que su activa militancia ha conseguido llegar a todas las capas sociales del país, además de movilizar a una gran parte de la ciudadanía. Como subrayaba Ebadi, esta exposición pública ha llevado a que muchos de estos disidentes se encuentren actualmente en prisión (Ebadi, 24-06-2009).

Una vez más, la consecución de los derechos democráticos, entre ellos el de la libertad de expresión, se muestra estrechamente vinculado a la lucha por la igualdad entre sexos. En este sentido, las mujeres han de enfrentarse a una doble barrera, extensible a cualquier ámbito de la vida cotidiana: la impuesta por la censura política, y la inferida de las prácticas sociales sexistas. En virtud de esta última situación, suelen ser las más perseguidas, como reflejan los informes de Amnistía Internacional, quien desde 2007 ha dado la voz de alarma al detectar un

\footnotetext{
${ }^{1}$ Para facilitar la lectura al lector no especialista, hemos optado por adecuar fonéticamente al castellano los términos y nombres propios originariamente en árabe y farsi.
} 
considerable aumento en el hostigamiento a periodistas y activistas de los derechos de la mujer $^{2}$.

Pese a todos los obstáculos, la aparición de una prensa feminista plural y reivindicativa desde finales de la década de los noventa, constituye un fiel reflejo no sólo de la agitación social, sino de la gran actividad de la mujer iraní en este campo, uno de los más expuestos, sin duda, a las represalias. Dentro de este ámbito, la revista Zanan, de Shahla Sherkat, se ha convertido en un referente para el periodismo comprometido con el feminismo islámico en todo el mundo.

\section{De la política al periodismo comprometido: Zan, de Faezeh Rafsanjani}

Una de las más ilustres ex alumnas de la Universidad femenina al-Zahra es Faezeh Hashemi Rafsanjani. Conocida periodista, miembro del Parlamento y activista de los derechos de la mujer, su notoriedad resulta aún mayor al ser la hija del ex presidente Akbar Hashemi Rafsanjani. Elegida miembro del parlamento por Teherán desde 1996 hasta 2000, desde julio de 1998 compaginó su actividad política con la periodística, al fundar el periódico femenino Zan (Mujer). Esta publicación, de tirada diaria, dedicada a concienciar a la población femenina de sus derechos, introduciendo así al público femenino en el debate entre modernistas y tradicionalistas desde su doble proyección de mujeres y ciudadanas.

Rafsanjani se atrevió a sobrepasar los límites al publicar, sin tapujos, asuntos que atañían directamente a la política y a la interpretación de las leyes y costumbres religiosas en beneficio del sistema patriarcal imperante. Denunciaba así una doble corrupción, la material y la espiritual, en la que las mujeres eran el colectivo más desfavorecido por las desigualdades provocadas por la cúpula más ultraconservadora de dirigentes políticos y religiosos. Con esta finalidad, se informaba a las mujeres de sus derechos y de sus deberes para con la sociedad, instándolas a reclamar un cambio en la legislación por la que se regían unas normas jurídicas y sociales discriminatorias, que afectaban también a la participación de la mujer en la vida política. La acogida dispensada fue muy favorable por parte de los lectores, en su mayoría mujeres. Zan se convirtió en muy poco tiempo en uno de los periódicos más leídos del país.

En este contexto, algunos otros medios liberales comenzaron también a mostrar ciertos signos de apertura con la inclusión de determinadas informaciones. En consecuencia, el Gobierno endureció considerablemente el control, lo que se tradujo en el incremento del

\footnotetext{
${ }^{2}$ El 7 de febrero de 2007, Amnistía Internacional mostraba su preocupación por la lo que calificaban de "oleada creciente de hostigamiento" (Amnesty International, 2007) a periodistas y activistas de los derechos de la mujer en Irán por parte de los funcionarios de seguridad. Y citaban, entre otros ejemplos, el episodio acaecido el 26 de enero de 2007. Ese día, los funcionarios del Ministerio de Información detuvieron a 15 mujeres periodistas para interrogarlas, cuando éstas estaban a punto de tomar un vuelo desde Teherán para asistir a un taller educativo sobre periodismo en la India. Doce de ellas fueron puestas en libertad varias horas después, con la advertencia de que no acudieran al evento si no querían sufrir consecuencias no especificadas a su regreso a Irán.
} 
número de diarios e informativos clausurados. Las voces contra dicha actuación fueron lideradas por el presidente de la República, Jatami, quien, en noviembre de 1998, se dirigía públicamente a los responsables gubernamentales y a los periodistas. Ante los primeros, defendió el derecho a la existencia de una prensa libre y crítica con la clase política ya que, entre otros factores, coadyuvaría a evitar la corrupción y al ejercicio honesto de sus cometidos al frente de sus respectivos cargos. A los segundos, les pidió que continuaran luchando "dentro del marco constitucional y del respeto a los valores islámicos" (Khatami, 1998).

Un mes más tarde, el propio Jatami daba ejemplo al apoyar la iniciativa de su anterior ministro del Interior, Adballah Nuri, quien había dimitido en junio de su cargo por las presiones de los conservadores. Nuri fundaba Khordad ${ }^{3}$, un nuevo periódico de corte liberalreformista cuyo título albergaba pocas dudas sobre su línea editorial, pues estaba destinado a promover el desarrollo de la sociedad civil y a la defensa de los derechos humanos. La Corte Especial de Clérigos, con autoridad para condenar a la disidencia y confiscar todo lo que fuera entendido como contrario al fiqh, condenó a Nuri, en calidad de editor-jefe, a cinco años de prisión. Su sucesor en la lucha y antiguo compañero de estudios, Yadollah Eslami, tomó el relevo con el mismo equipo de Nuri a través del diario $\mathrm{Fath}^{4}$, que también fue clausurado en el año 2000.

La misma suerte correría Zan, pero en su caso, el proceso fue mucho más rápido, pues apenas estuvo en activo un año. La valentía de Faezeh la llevó a publicar informaciones sumamente incómodas para el aparato estatal que otros medios, dirigidos por hombres, no se habían aventurado a tratar.

Buena prueba de ello es que osó publicar los detalles de un asunto especialmente escabroso: el intento de agresión a dos políticos reformistas (el anterior ministro del Interior, el citado Nuri, y el ministro de Cultura de entonces, Atallah Mohajerani), a manos del Jefe de los servicios de Policía e Inteligencia del Estado, el coronel Muhammad Naqdi. Esto era, al menos, lo que se infería de las entrevistas realizadas a varios testigos presenciales, quienes no dudaron en implicar a Naqdi en los hechos (Anón, 1998).

\footnotetext{
${ }^{3}$ El término proviene del avestánico y designa el concepto zoroástrico de "perfección”, además de uno de los meses del calendario persa. Es en esta última acepción, en la que se hace referencia al conocido como "Movimiento del 2 de Khordad" (equivalente al 23 de mayo de 1997). Se trata del movimiento que coaligó a los dieciocho partidos que componían el Frente Reformista en torno a la candidatura de Muhammad Jatami, y a su victoria en los comicios de 1997. El simbolismo de que la elección se produjera en el "mes de la perfección", fue considerado por muchos como un buen augurio y contribuyó a fortalecer las esperanzas depositadas en el nuevo presidente.

${ }^{4}$ El término proviene del árabe Fatiha (lit. "la que abre"), y se refiere a la primera azora del Corán. El guiño lingüístico de Eslami, al emplear un término estrictamente religioso que lo situaría en la más pura ortodoxia, escondería sin embargo un contenido subversivo que podría interpretarse de diversas maneras. En primer lugar, como "inicio de algo, de una nueva era", en consonancia con el espíritu del desaparecido Khordad. En segundo término, el hecho de establecer una vinculación con la revelación coránica puede implicar también un carácter reivindicativo de su relectura e interpretación. Y por último, en un sentido histórico, la revelación coránica supuso una gran revolución en su tiempo, que no fue bien aceptada por algunos próximos al Profeta. Cabría también una reflexión en torno a este rechazo inicial en las esferas más conservadoras.
} 
Las autoridades más conservadoras no tardaron en reaccionar: imputaron al diario y a su directora los cargos de injurias y calumnias. Rafsanjani fue declarada culpable por el tribunal y Zan fue clausurado en 1999, justo después de haberse publicado viñetas como la que, en abril de 1999, mostraba a una prensa convertida en Némesis y representada en un hacha, que cortaba cabezas de corruptos y represores (Karimian y Bahrampour, 1999: 38-39).

Una década después, en 2009, su fundadora volvía a ser actualidad. En esta ocasión, por participar en un acto de protesta en Teherán a raíz de las elecciones generales de ese mismo año, siendo arrestada y liberada poco después. Lo que demuestra que la transformación de la sociedad iraní hacia un sistema democrático se encuentra indisolublemente vinculada al reconocimiento de los derechos de la mujer y a la participación del colectivo en dicho proceso (Paidar, 2001: 27).

Con Rafsanjani hemos hecho alusión a dos de las prácticas más comúnmente empleadas contra la actividad desplegada por el activismo femenino: la imputación de cargos penales y la clausura forzosa del órgano de expresión en cuestión. El eufemismo más comúnmente empleado para esta última práctica es el de "la no renovación de licencia de apertura", es decir, que el periódico o el medio en cuestión no ha sido cerrado, sino que su responsable no ha conseguido obtener la renovación de la licencia ante las instancias administrativas correspondientes. De esta forma, el cierre es anunciado en los medios en términos de incumplimiento de las condiciones que permitían su apertura.

Pero existen otros métodos mucho más rápidos y expeditivos, como es la detención in extremis de militantes que van a salir del país para participar en actos culturales, incluyendo la recogida de galardones y otros reconocimientos de carácter internacional. Entre las que han padecido esta medida y, en no pocas ocasiones, se encuentran Parvin Ardalán y Shahla Sherkat.

La inconstitucionalidad de estas acciones resulta flagrante, pues se produce tras haber sido tramitados y concedidos todos los permisos pertinentes, es decir, sin base legaladministrativa alguna. En el mejor de los casos, como sucedió con Sherkat en 2009 con motivo de su visita a España acompañada de Azam Taleghani, ambas pudieron viajar. Pero la interpretación de algunas de las declaraciones de Shahla en nuestro país la llevaron a ser arrestada a su regreso a Teherán. A todas ellas se les han clausurado sus medios de expresión pero, al igual que Rafsanjani, continúan luchando por los derechos de la mujer. Veamos bajo qué circunstancias.

\section{Parvin Ardalán y su revista digital Zanestan}

"The combination of religion and state was a combination of religious and political discrimination against women. As the basis for this attitude on the social level was laid out, many men kept quiet about this enormous discrimination. The first victims of the religious state were women living with patriarchal politics, and patriarchal religion" (Daragahi, 2010). 
En consecuencia, "Si eres una mujer y vives en Irán, te darás cuenta muy rápidamente de que tienes que luchar para conseguir tus derechos" (Van den Abeele, s.d.). Con estas palabras podría resumirse la trayectoria de Parvin Ardalan, una reconocida escritora y periodista, que desde 1990 lideraba a través de su ONG Markaz-e Farhangi-ye Zanan (Centro Cultural de Mujeres), toda una serie de iniciativas encaminadas a la erradicación de la discriminación de género ${ }^{5}$. Entre ellas, destacamos la creación del magazine digital Zanestan (La Ciudad de las Mujeres) y la Campaña "Un Millón de Firmas para la Igualdad de Derechos" (Sherkaloo, 2005).

El origen de esta campaña, como relata la propia Ardalán, se remonta a 2003, cuando a raíz de una manifestación que fue duramente reprimida, se sentaron las bases sobre las que continuar la lucha: "After that, we arrived at the conclusion that we had two choices: either to give up, or, to find other methods of street action. We wanted both to involve people in issues related to women and to engage in street activity, because this kind of work allowed us to break out of the closed atmosphere of work within the group - one is seen and has an audience" (Daragahi, 2010).

La puesta en marcha del proyecto comenzó oficialmente el 27 de agosto del 2006, durante un seminario titulado "El impacto de las leyes en la vida de las mujeres", y tenía como principal objetivo acabar con todas las discriminaciones legales basadas en el género, como por ejemplo las leyes de divorcio y de la custodia de los hijos, todas ellas arraigadas en la legislación iraní. Seguían así el camino de sus compañeras marroquíes, a las que Shahla Sherkat se ha referido en varias ocasiones como ejemplo a seguir cuando, en 2003, consiguieron la aprobación de una nueva Mudawana o código de familia marroquí (MirHosseini, 1993: 84-114 y Ruiz de Almodóvar, 2006: 357-367). Este cambio histórico en Marruecos, unido a la concesión del Nobel a Ebadi y a la presidencia de un reformista como Jatami, dieron un nuevo impulso a las actividades emprendidas desde la sociedad civil.

Con el mismo empuje que sus hermanas marroquíes, pero mayores impedimentos debido a las peculiaridades del sistema político de la República Islámica, un gran número de voluntarias, cuyas edades oscilaban entre los veinte y veinticinco años - de nuevo el movimiento estudiantil—, recorrieron el país para informar de la iniciativa y recoger las firmas necesarias. Una de las primeras en adherirse a la petición fue Shirin Ebadi, que acababa de recibir el Nobel, contribuyendo así a la repercusión del proyecto. Otras destacadas figuras intelectuales del país, como Nushin Ahmadi Khorasani (periodista y activista, miembro fundador del Centro Cultural de Mujeres) o la poetisa Simin Behbhani (nominada al Premio Nobel de Literatura en 1997), ya habían mostrado su apoyo a esta y a otras iniciativas anteriores de Ardalán.

Más allá de la reforma legislativa inmediata, lo que se pretendía era provocar un cambio en la actitud de los ciudadanos hacia estas leyes, en la línea de lo que hemos expuesto anteriormente: que la opinión pública se concienciara del hecho de que promover los derechos

\footnotetext{
${ }^{5}$ Incluyendo una página Web aún operativa: http://www.badjens.com [12-12-2011].
} 
de las mujeres conlleva de manera más amplia una promoción y la defensa de los valores democráticos.

Con esta finalidad, se organizaron talleres de sensibilización y tertulias, que se acompañaron de una amplia difusión de folletos informativos y del empleo de las nuevas herramientas tecnológicas, como Internet, para difundir los mensajes de la campaña ${ }^{6}$. Sobre dichos panfletos, Ardalán menciona que pudieron distribuirlos antes de ser detenidas:

\begin{abstract}
"We were going to use the pamphlet called "The effect of laws on the lives of women" that we had prepared for the demonstration. Before the demonstration, since we knew we may be arrested, we dropped the pamphlets into people's mailboxes. Some one thousand pamphlets had already been distributed in this way. We had come to the conclusion that the distribution of the pamphlets was good as a relatively risk-free way of expressing our goals. It was an effective way of raising feminist awareness in relation to legal discrimination, as the pamphlet dealt with major discriminatory arrangements in the existing legal structure" (Daragahi, 2010).
\end{abstract}

La originalidad y la fuerza del movimiento residieron en haber logrado integrar a mujeres y hombres de edades diferentes, de orígenes sociales y culturales diversos en torno a estos principios, y evidenciar que éstos no están reñidos con la tradición islámica ni con el sistema político iraní:

"This process has been going on over the last three years. The initiators were the middle-class activists of the women's movement, but before long, the activists of the workers and students movements also got involved. Since collecting signatures took place in public spaces and work places, it broke the class barrier. We collected signatures in prisons, courtrooms, undergrounds, buses and collective taxis" (Daragahi, 2010).

El éxito de la campaña se tradujo en que los sectores más conservadores decidieron emprender acciones legales contra sus principales líderes, entre ellas Ardalán. En 2007, ella y otras treinta y tres militantes fueron sentenciadas a tres años de cárcel "por haber difundido propaganda contra el Estado". De hecho, las actividades de las personas que tomaron parte activa de la campaña han sido prohibidas y sus pasos continúan estando bajo vigilancia, proceso que puede acabar incluso con la detención, muchas veces sin la atribución de cargo alguno.

En el transcurso del juicio que la condenaría a tres años de prisión, en marzo del 2007, Ardalán fue galardonada con el Premio Olof Palme, que cada año se otorga a una personalidad por su labor en el ámbito de la paz, de la igualdad o de la seguridad. Se reconocían así sus más de quince años de trayectoria en pro de la igualdad de derechos entre mujeres y hombres en Irán. Parvin Ardalán no pudo recoger el galardón al serle prohibida la salida del país en el último momento: las autoridades iraníes la obligaron a salir del avión y le confiscaron su pasaporte al ser acusada de "poner en peligro la seguridad nacional" (Daragahi, 2010). Se trata

\footnotetext{
${ }^{6}$ Cuenta con una página Web en inglés a través de la cual podemos conocer las últimas noticias al respecto: http://www.campaignforequality.info/english/ [10-10-2011].
} 
de un cargo común en Irán contra las activistas del movimiento feminista y también contra activistas de otros movimientos sociales, como el movimiento estudiantil.

Esta circunstancia no impidió que, el 6 de marzo, la activista apareciera en la pantalla del televisor leyendo su discurso de agradecimiento. Su mensaje fue transmitido durante la ceremonia de entrega del premio, en directo, y desde Teherán. Los intentos de contención de su gesto no disimularon la tensión imperante, que trató de plasmar en un texto cuya lectura, al igual que el de Ebadi (2003), recomendamos.

En el caso de Ardalán, el mensaje estaba destinado, fundamentalmente, al consumo interno. Fue un discurso crítico, lleno de significativas pausas, silencios y miradas que comunicaban mucho más que las palabras. Estas últimas, dadas las circunstancias, debían moderarse. No obstante, tanto en su lenguaje gestual como en el textual, parecía responder directamente a los responsables de la situación, tanto a los compañeros de lucha como a sus verdugos, frente a los que reiteró su compromiso y perseverancia en continuar con la lucha, pues a pesar de las dificultades, "nunca renunciaría a sus ideales" (Ardalán, 2007).

"Un millón de Firmas" recibió también numerosos galardones, entre otros, el Premio Simone de Beauvoir de las Mujeres para la Libertad, el Premio de Reporteros Sin Fronteras (RSF) y el Premio Deutche Well por la página Web creada para la campaña. Al igual que la concesión del Nobel a Shirin Ebadi, estos premios han proporcionado un reconocimiento internacional a los movimientos de mujeres en Irán. Con ellos se han albergado y consolidado las esperanzas de las activistas de dentro y fuera del país: el camino emprendido no sólo no tiene marcha atrás, sino que llegará algún día al final de su recorrido.

El éxito de "Un Millón de Firmas" no hubiera sido posible sin la campaña de concienciación e información que desde 1990 lidera Ardalán a través del Centro Cultural de Mujeres, convertido en un instrumento fundamental para el análisis de la situación de las mujeres en Irán. De dicho centro, nacía, en 2005, el primer magazine bi-mensual online dedicado a los derechos de las mujeres: Zanestan (La Ciudad de las Mujeres), con Ardalán como editora.

Zanestan fue la respuesta de Ardalán al cierre de las publicaciones escritas sobre la misma temática, convirtiéndose en un marco de referencia donde se trataban todas las cuestiones relacionadas con la discriminación que sufría la mujer en la sociedad iraní: desde el matrimonio, pasando por la prostitución, la educación, el sida o la violencia de género. En cierta manera, se establecía una continuidad en formato digital con su hermana Zanan (Mujeres), pionera en el periodismo feminista, que ya llevaba publicando en prensa escrita, desde febrero de 1992, sobre estos mismos temas.

En la misma línea de los panfletos repartidos durante la campaña "Un Millón de Firmas", el análisis de la discriminación femenina en la legislación, es la piedra angular en torno a la que se articulan las reivindicaciones:

"Marriage: The first step a woman must take in marriage, according to the existing law, is to satisfy the condition of the father's consent. For marriage, virgin women must have their father or 
paternal grandfather's permission. With the courts' permission, a father can marry his daughter, even before the age of thirteen, to a seventy-year-old man.

Divorce: According to the law, divorce is the exclusive right of a man, and a man can divorce his wife whenever he pleases.

Multiple wives for men: A man can have four aghdi (permanent) wives and infinite sighehi (temporary) wives.

Age of criminal responsibility: The age of criminal responsibility for girls is nine lunar years and for boys fifteen lunar years.

Citizenship rights: According to Iranian law, the citizenship of a woman does not transfer to her child. If your father is Iranian, you too are considered Iranian. But, having an Iranian mother does not make you an Iranian citizen.

Inheritance: According to civil law, after the death of the father and mother, sons receive two times as much in inheritance as daughters.

Honour killings: Among the discriminatory laws, one can note the law that gives a man permission to kill his wife whenever he sees her in bed with another man, and the law will not punish this man.

Bearing witness: There are some crimes in which women can not testify. In the cases where a female witness is accepted, the testimony of two women equals that of one man. Then, other discriminatory laws like compulsory prescribed dress for women and stoning" (Daragahi, 2010).

También abrió una página en la Red: Iranian Feminist Tribune, pero tanto la revista como la web fueron clausuradas por orden judicial en noviembre de 2007, cierre que se hizo extensivo a su ONG, de donde provenían ambas iniciativas. También condenaron a una de sus ciberperiodistas, Maryam Husseinkhah, al pago de una fianza equivalente a 95.000€, por haber publicado un artículo sobre mujeres en prisión.

Aunque el soporte digital de Zanestan constituía una burla a la censura imperante, Ardalán se vio obligada a emplear nuevas estrategias para impedir su clausura definitiva. Como otras ciberfeministas, optaron por reabrir sus páginas bajo otro nombre y licencia. De forma que el testigo de Zanestan fue recogido por Tagir Bary Barbary (Cambio para la Igualdad), de contenidos y formato similares a su antecesor ${ }^{7}$.

A pesar de estos intentos, las nuevas tecnologías tampoco han escapado al control de los medios más ultraconservadores. En septiembre de 2008, RSF informaba de la detención de Ardalán, junto a otras tres compañeras (Jelveh Javaheri, Maryam Husseinkhah y Nahid Keshavarz, todas ellas periodistas, con varias condenas previas, y miembros del equipo de Zanestan y de Tagir Bary Barbary), acusadas de violar el artículo 500 del código penal islámico al "publicar informaciones en contra del régimen". En virtud del citado artículo, quien haga propaganda contra el Estado puede ser condenado de tres meses a un año de cárcel. Shirin Ebadi defendió en el proceso a las cuatro ciberfeministas, de las que comentaba a RSF:

\footnotetext{
${ }^{7}$ Tagir Bary Barbary cuenta con una página Web cuya versión inglesa puede consultarse en: http://wechange.org/english/ [11-10-2011].

${ }^{8}$ Reporteros Sin Fronteras (2008) denunciaba la situación en los siguientes términos: "Estas cuatro periodistas publican sus artículos en el Internet porque han censurado sus revistas. Son víctimas de un auténtico ensañamiento de las autoridades, que las citan frecuentemente en los tribunales para interrogarles sobre sus actividades. Están sufriendo una verdadera discriminación. Pedimos al gobierno que deje sin efecto las acusaciones que les imputa".
} 


\begin{abstract}
"Han sido condenadas simplemente por publicar informaciones y por criticar algunas leyes injustas con las mujeres iraníes. Estoy preocupada porque veo que la situación está empeorando. Si el Parlamento ratifica la nueva ley que aumenta las penas para los delitos cometidos contra la seguridad moral de la sociedad, a los bloggers podrán condenarles a penas de cárcel. Resulta desolador" (IFEX, 2008).
\end{abstract}

A pesar de este sombrío panorama, que los polémicos comicios de 2009 no han hecho sino confirmar (Mir-Hosseini, 2006), Ardalán ha conseguido romper con muchos estereotipos y ha demostrado que las mujeres iraníes quieren, saben y pueden defender sus derechos como muchas mujeres en el mundo:

\begin{abstract}
"Estoy orgullosa de ser una mujer laica que pertenece a un movimiento con una trayectoria de más de cien años de lucha y de resistencia para conseguir los derechos de las mujeres. Durante más de cien años, nosotras también, como nuestras hermanas en el mundo, hemos luchado para conseguir nuestros derechos humanos más básicos" (Van den Abeele, s.d.).
\end{abstract}

Para ella, como para tantas otras, la igualdad de género se inserta en las bases de un sistema político laico y democrático, totalmente ajeno a la instrumentalización de la religión como elemento legitimador de la discriminación de género:

\footnotetext{
"The idea of man as the legally superior sex, and the head of the household as well as the person to whom the woman should submit sexually, was transferred to the political sphere and the role of the state. Thus, just as the man is in control of the woman, the state is the keeper of this Islamic symbol by controlling the woman's body by enforcing the veil, gender separation in schools and universities, on the streets and means of public transport.

If this control is threatened then, the assumption is, it is a threat to Islam, and by extension, to the Islamic state. Any incursion on this control is seen as a threat. Just as according to Iranian law the man is the measure for humanity, the woman is the measure for discrimination. The sexualisation of politics was from the very beginning the strategy of the Islamic Republic" (Daragahi, 2010).
}

Se adscribe así a la línea del feminismo islámico de tendencia más bien laicizante aunque en una línea más moderada de la que expone, por ejemplo, la egipcia Nawal Saadawique propugna la necesidad de reinterpretar la tradición religiosa pero, sobre todo, su desvinculación de las instituciones políticas.

En este sentido, Azam Taleghani y Shahla Sherkat dan un paso más dentro del denominado feminismo islámico. Ambas combaten los argumentos religiosos con los que se perpetúa la discriminación femenina con las mismas armas empleadas por sus coetáneos masculinos: los textos religiosos y su interpretación. Su discurso, basado en la yihad de género, presenta, por tanto, el valor añadido de utilizar las mismas estrategias empleadas durante años por los más conservadores para defender el propósito contrario: la reforma y la igualdad. Si el elemento religioso supone un medio definitivo para legitimar argumentos y posiciones en torno a cualquier aspecto de la vida cotidiana, ellas sitúan sus reivindicaciones en el mismo plano que el nacimiento y desarrollo del Islam, al que no dudan en calificar de auténtica revolución social en su época. 


\title{
5. La lucha de Azam Taleghani a través del semanario Payam-e Hajar
}

Azam Taleghani es periodista e hija del conocido ayatolá Mahmud Taleghani, muy cercano a Jomeini, que falleció poco después de la Revolución. Al igual que Faezeh Hashemi Rafsanjani, trató de continuar la carrera política de su padre, sin conseguir llegar más allá de miembro del Parlamento pues, como hemos mencionado, su candidatura a las elecciones presidenciales fue vetada en 1997, 2001 y en 2009, por el Consejo de Guardianes ${ }^{9}$. Al igual que su coetánea, Zahra Rahnavard, se opuso al régimen del Shah, sufriendo prisión, y acabó por apoyar decididamente la llegada de la Revolución Islámica, ante cuya evolución ambas mostraron su desacuerdo. De hecho, renunció a su condición de parlamentaria al acusar a sus miembros de estar muy alejados de la sociedad y del Islam ${ }^{10}$.

$\mathrm{Su}$ activismo a favor de los derechos humanos ${ }^{11}$, y más concretamente, los de la mujer musulmana, lo ejerce como presidenta de la Sociedad de Mujeres de la Revolución Islámica de Irán (organismo equivalente al Instituto de la Mujer), fundadora de Jame'e Zanan Mosalman (Sociedad de Mujeres Musulmanas) y, desde 1980, editora del semanario Payam-e Hajar (El mensaje de Hajar $)^{12}$, publicado en inglés y en farsi.

Este último fue clausurado en el año 2000. Se trataba de un semanario de corte tradicional, enfocado a difundir el papel de la mujer en el Islam y sus derechos en función de una correcta interpretación del mismo. En 2006, Taleghani relataba su experiencia a tenor del cierre del semanario:

\begin{abstract}
"When the weekly publication Payam Hajar was banned, we requested another publication license which was granted but was not announced and given to us. When we asked for the reason why they did not pass it to us, the response was that it was simply not advisable for us to have it. I have repeatedly contacted the press assistant in the Ershad ministry during Khatami and Ahmadinejad presidency, but have been told that they will need a guarantee" (IHRAG, 2006).
\end{abstract}

Taleghani imparte conferencias sobre las mujeres y los medios de comunicación, contra la violación de los derechos humanos y la necesidad de regresar a las fuentes de la tradición islámica, para reivindicar un programa de reformas que solvente ambas cuestiones. Desde esta

\footnotetext{
${ }^{9}$ Sobre la candidatura de 1997, véanse las dos entrevistas concedidas por Taleghani a Shahla Sherkat, y publicadas en Zanan, en abril y junio de ese mismo año. Para el veto de 2009, consúltese Esfandiari (2009).

${ }^{10}$ La carta que dirigió el 26 de agosto de 2009 a los miembros del Parlamento puede consultarse en uno de los muchos blogs que encontramos en la Web: http://iranfacts.blogspot.com/2009/08/azam-taleghaniscolds-iranian-clerics.html [12-12-2011].

${ }^{11}$ Véase como ejemplo su actuación en 2003 en defensa de los prisioneros políticos y las denuncias de malos tratos y vejaciones a los que son sometidos en http://www.payvand.com/news/03/aug/1071.html [11-10-2011].

${ }^{12}$ En la misma línea que El camino de Zaynab, de Rahvanard, El camino de Hajar, hace referencia a otra mujer destacada en la historia del Islam. Se trata de la concubina de Abraham y madre de Ismael, de donde tradicionalmente y, según los textos sagrados, provienen los árabes. La madre del fundador de la estirpe es la figura elegida intencionadamente por Taleghani para mostrar el papel de la mujer en la historia islámica y, sobre todo, la línea editorial de la publicación.
} 
apreciación, su argumentación se inscribe en los llamados movimientos feministas islámicos de corte moderado-reformista, situándola en un estadio intermedio entre las posiciones defendidas por Rahvanard y por las reformistas de tendencia laicizante como Ebadi o Ardalán.

Por lo que respecta a Sherkat, cabría adscribirla al feminismo islámico basado en la yihad de género, situándose en una posición similar a la de Taleghani en muchos aspectos, pero, a diferencia de la primera, la revista de Shahla da cabida a los presupuestos laicizantes representados, entre otras, por Ebadi y Ardalán.

\section{La valiosa contribución de Shahla Sherkat y su revista Zanan}

Shahla Sherkat es una de las figuras más emblemáticas del movimiento feminista en Irán. Infatigable escritora, además de psicóloga y periodista, su lucha por los derechos de la mujer iraní sin renunciar a su identidad y tradiciones culturales y religiosas, la ha convertido en la principal exponente del periodismo militante en su país y en pionera del periodismo feminista.

Simpatizante de la Revolución Islámica de 1979, fue directora durante ocho años de Zan-e Ruz (Mujer de Hoy), revista femenina de la que fue cesada, según afirma, por tener una actitud excesivamente militante con los derechos de las mujeres (Sherkat, 2009). Se percató entonces de que el periodismo iraní adolecía de un acercamiento serio y riguroso a la situación de los derechos de las mujeres, y decidió llenar este vacío con Zanan (Mujeres). Esta última se convirtió en la primera revista feminista independiente escrita por y para mujeres, aunque abierta a cualquier interesado en conocer la situación del colectivo:

\footnotetext{
“Quand j'ai commencé à faire du journalisme dans le domaine des femmes, j'ai découvert progressivement et appris à connaître leurs problèmes. De nombreuses femmes venaient au bureau de la revue en quête de conseils. Cela m'a encouragé à mener mes recherches, à étudier les lois concernant les femmes pour pouvoir les conseiller. J'ai donc découvert, peu à peu, que la situation des femmes était très, très sensible au sein de la société. J'ai aussi découvert l'existence d'une discrimination sexuelle à leur encontre, aussi bien dans la famille que dans la société" (Haddad, 2009).
}

Adoptando un lenguaje bastante espiritual, en la línea del sufismo, Sherkat enfatizaba en su primer editorial la autonomía y la capacidad de elección como el primer pilar sobre el que se sustenta la libertad, invitando a toda la sociedad iraní, dentro y fuera del país, a participar en sus páginas (Sherkat, 1992: 2-3). Se erigía así en una ventana abierta al debate público, en el que se daban cita tendencias de toda clase: laicas e islámicas, moderadas y reformistas. $\mathrm{Su}$ línea editorial quedaba definida en los siguientes términos:

"We believe that the key to the solution of women's problems lies in four realms: religion, culture, law, and education. If the way is paved in these four principal domains then we can be hopeful of women's development and society's advancement" (Sherkat, 1992: 2). 
Tras doce años de continuado trabajo, la vocación aperturista se reflejó en la creación de su edición digital, en enero de 2003, coincidiendo con el número 100 de la revista ${ }^{13}$. En este formato llegó a editarse hasta el número 152, el último de la desaparecida Zanan.

Ideológicamente, la definiríamos como una revista de tintes reformistas cercanos a los planteamientos laicos y musulmanes liberales. De periodicidad mensual, y con una tirada de cuarenta mil ejemplares frente a los cinco mil de sus más cercanos competidores (Tohidi, 2008), abordaba temas sociales y políticos, además de cuestiones consideradas tabúes: leyes sobre el divorcio, custodia de los hijos, abusos físicos y verbales, el incremento en los casos de sida, mitos y realidades sobre la prostitución, la discriminación en las Universidades, etc., consiguiendo evitar, en gran medida, la censura.

De hecho, a pesar de que los más de treinta colaboradores de la revista, empezando por su directora, han sido objeto de amenazas, denuncias y en ocasiones han sufrido arresto, Zanan ha podido seguir publicándose durante dieciséis años, desde febrero de 1992 hasta febrero de 2008. Todo un logro, si tenemos en cuenta la exigua vida de algunos de los medios a los que hemos aludido con anterioridad, y las restricciones impuestas a los medios de prensa.

La clausura definitiva de la revista, un mes antes de celebrarse las elecciones al Parlamento, se debió, oficialmente, a que proyectaba una imagen sombría del régimen. Una acusación de la que Sherkat se defiende:

"Zanaân a été fermé avec pour titre d'accusation: donner une image sombre et noire de la situation de la femme en Iran. Ce n'était pas notre but. Nous voulions juste présenter les problèmes et les difficultés dans la vie des femmes afin d'y apporter des solutions. Il était question de sensibiliser l'opinion publique et les autorités à cette situation. En même temps, si notre but était de présenter ces problèmes, on présentait aussi des femmes qui avaient eu du succès dans leur vie professionnelle. On reflétait leurs expériences pour montrer qu'en Iran, comme partout ailleurs, il y a une panoplie de femmes avec des parcours parfois difficiles mais aussi des modèles à suivre" (Haddad, 2009).

Para Sherkat, el cierre ha sido motivado por la censura del régimen:

"Unfortunately, in a society that has yet to reach political maturity and where democracy has not become institutionalized, political leaders see the survival of their system in the envelopment of a protective cover against criticism. They seem unaware that tossing ash on fire only hides its glow, and it resurfaces and burns when least expected. This outlook that exists in certain sectors of Iran's governing structure led them to shut Zanan after accusing the magazine of portraying the situation of women in a "dark light." What our journalists did to echo the needs and problems of women (with the intent of building awareness among Iranians and public officials so solutions could be found) was interpreted as being a darkened portrayal. To prevent our revelations about women and their issues from disturbing the public's consciousness, Zanan was closed" (Sherkat, 2009).

\footnotetext{
${ }^{13}$ La dirección empleada: www.zanan.co.ir se encuentra fuera de servicio al ser clausurada junto a la edición impresa.
} 
Y es que su proyección nacional e internacional la convertía en un referente para conocer la actuación de la mujer iraní en todos y cada uno de los órdenes de su vida cotidiana, recogiendo cualquier noticia o iniciativa relacionada con el colectivo.

Además de presentar situaciones reales y ofrecer soluciones a los problemas que se planteaban, también proponía intensos debates en torno a la discriminación jurídica de las mujeres en función de su sexo, y reivindicaba la adopción de una serie de medidas de carácter estructural para erradicar estas prácticas. Con esta finalidad, prestaba su voz a los testimonios de mujeres que habían conquistado alguna esfera del espacio tradicionalmente masculino: abogadas, pintoras, actrices, médicas, deportistas, escritoras y militantes feministas de los derechos humanos tan reputadas como Ebadi o Taleghani.

Otra gran contribución de la revista reside en su intención de eliminar los prejuicios existentes, tanto por parte de los musulmanes conservadores más reaccionarios hacia el feminismo, como de los ciudadanos iraníes y musulmanes, en general, en torno al mundo occidental. En este sentido, Zanan se ha convertido también en un valioso interlocutor para ambos grupos. Ha potenciado los lazos y vínculos culturales a través de traducciones de autoras occidentales, y también fomentando el intercambio intelectual entre las feministas islámicas y las feministas occidentales, así como el debate y la cooperación entre las distintas tendencias del feminismo laico y el religioso (islámico). Como menciona su directora:

\footnotetext{
"When I started Zanan I just wanted to use my 10 years' experience of women's issues. It took courage. The word feminism was used as a swearword. I didn't want to become known as a defender of feminism, I just wanted to talk about it. Feminism is still a new phenomenon here: we need to use it to create unity, to encourage women to protest together against gender inequality. That's why I refuse to attach any adjective to the word, such as Islamic or secular. I haven't got much time for labels. I am quite simply a feminist" (Kristianasen, 2004).
}

Asimismo, ha jugado un papel fundamental para los movimientos islámicos de mujeres, pues ha sido pionera en realizar una reinterpretación y reformulación de género de los textos religiosos y jurídicos, además de ofrecernos un detallado escenario del universo femenino, al que han contribuido conocidas defensoras de un sistema secular, como Mehrangiz Kar o Shirin Ebadi (Moghadam, 2002: 1145) o teólogos feministas de la talla de Mohsen Saidzadeh, quien empleaba un pseudónimo femenino. Como señalan algunos autores (Mir-Hosseini, 2000: xv), la colaboración de Saidzadeh con Zanan desembocó en una serie de artículos y comentarios sobre jurisprudencia islámica enfocados a la cuestión femenina, que fueron recibidos con gran suspicacia por los medios más conservadores.

Pero no sólo ha dado voz, ha creado conciencia, y ha fomentado, además de la solidaridad femenina, un espíritu crítico con las bases sobre las que descansa la República Islámica. Los presupuestos patriarcales que han dominado las interpretaciones de los textos religiosos, y con ello la segregación de sexos, han sido cuestionados en reiteradas ocasiones desde sus páginas por profesionales de muy diversos ámbitos. Incluso, su directora ha ido un paso más allá, al incitar a los lectores a que realicen un ijtihad conducente a una interpretación moderna del Islam. Las implicaciones inferidas de esta última consideración resultan 
abrumadoramente reformistas: Sherkat propone a las mujeres que ejerzan su derecho a emplazar sus necesidades en el campo de la interpretación de los textos, lo que supone "acabar con el monopolio del clero en estas cuestiones" (Najmabadi, 1998a: 71).

Además de la reinterpretación del canon islámico, cada número de la revista incluía diversas secciones fijas dedicadas a problemas y contenciosos sociales, debates, entrevistas, actividades culturales, crítica literaria y cinematográfica, aspectos relacionados con la salud de la mujer y la práctica deportiva, la sexualidad femenina, etc. Y todo ello a través de un lenguaje que juega, a veces, con la homonimia y el doble sentido de las palabras, recurso muy empleado también en lengua árabe.

A través de sus contenidos, Zanan transmitía al resto de mujeres iraníes que los valores democráticos, en los que se inscribe la igualdad de género, estaban estrechamente vinculados a los valores islámicos; que la convergencia entre tradición y modernidad no sólo eran deseables sino necesarias en el Irán actual; y que, a pesar de las dificultades, se estaban consiguiendo algunos logros, por lo que la lucha no debía abandonarse, puesto que en ella no estaban implicadas solamente las mujeres, sino toda la sociedad iraní al completo.

Otro de los méritos de la revista es el de haber ofrecido la oportunidad a jóvenes periodistas, como Parastu Dokoohaki, Shadi Sadr, o Roya Karimi-Majd, quienes han realizado reportajes realmente provocativos no sólo sobre las prácticas sexistas y represivas, sino también sobre algunos de los males que aquejan a la juventud actual: pobreza, drogadicción, depresión, episodios de violencia, incesto, violaciones pre y post-matrimoniales, cirugía estética, adicciones diversas, etc.

Prueba de la relevancia y significación alcanzada por Zanan, es la publicación de un libro dedicado al papel desempeñado por esta revista con el sugestivo título de Zanan, le journal de l'autre Iran (París, CNRS Éditions, 2009). En sus páginas se recogen los extractos de los artículos más significativos, así como algunas portadas de cada número y parte de las imágenes, igualmente ilustrativas, que tuvieron cabida en un espacio diseñado por mujeres para mujeres. De su lectura, se infiere la efervescencia y vitalidad del movimiento feminista, su incansable lucha y los innumerables obstáculos a los que deben hacer frente las mujeres iraníes en su vida cotidiana.

Las sufridas por la propia Sherkat para mantener a flote la revista constituyen una buena muestra de la situación. Entre las medidas que coadyuvaron a presionarla para el cierre de la revista estaba la cuestión económica. La independencia ideológica de Zanan se debía a que su única responsable era ella, ya que no dependía de ningún otro socio. Sin embargo, el mantenimiento económico de la publicación pronto resultó un problema que a duras penas se ha conseguido solventar con unos cuantos anunciantes de cosméticos y otros productos femeninos.

Por otra parte, la campaña de hostigamiento a la prensa reformista comenzó a afectar a la revista desde su misma creación. Entre las acusaciones más manidas, la de creación de un movimiento de oposición al Gobierno, que era castigado por una banda de pistoleros anónimos con la consabida violencia: rotura de cristales y mobiliario, amenazas, etc., sin que la Policía 
interviniera, a pesar de los reiterados llamamientos. En consecuencia, Sherkat decidió evitar nuevas represalias y renunció a cualquier símbolo o icono que pudiera revelar el paradero de las oficinas de la revista, manteniendo así la cautela en torno a su ubicación (IWMF, 2005).

También tuvo que defender, en calidad de directora de contenidos, determinados artículos que fueron llevados a los tribunales por su contenido subversivo. Entre ellos, una serie de escritos bastante controvertidos para los ultraconservadores sobre la ley islámica y la mujer, escritos por los citados Shirin Ebadi, Mehrangiz Kar o Mohsen Saidzadeh. Como en tantas otras ocasiones, Sherkat tuvo que explicar ante el Tribunal de Prensa la línea ideológica en la que se inscribían. El loable esfuerzo por evitar cualquier objeción, obtuvo sus frutos. Finalmente, los cargos fueron retirados.

En otras ocasiones, las acusaciones eran mucho más concretas. En 1987, Sherkat fue requerida por la Corte por haber publicado una historia sobre una chica que fue arrestada en una playa del Caspio por no haberse cubierto completamente el pelo. También en esta ocasión, fue exonerada de responsabilidades (IWMF, 2005).

La censura traspasa también las fronteras, por lo que Sherkat ha de ser siempre sumamente cuidadosa con las expresiones que emplea. Ya en enero de 2001 fue sentenciada a cuatro meses de cárcel por haber participado en un foro organizado por el Heinrich Boll Institute de Berlín, con una conferencia titulada "El futuro de la reforma en Irán”. El cargo que se le imputó fue el mismo que a Ardalán cuando pretendía recoger en 2007 el Premio Olof Palme: haber atentado contra la seguridad nacional al sugerir que el código de vestimenta islámica debería constituir una recomendación, y no una imposición (Kristianasen, 2004). La pena impuesta fue conmutada por una sanción económica equivalente a dos meses de trabajo.

Esta falta de libertad de expresión, aún en el extranjero, no ha sido a veces entendida por los interlocutores occidentales, quienes a menudo la han tildado de mostrarse demasiado moderada en su discurso. En el fondo, lo que subyace en estas consideraciones es la vigencia de una serie de estereotipos potenciados desde una visión occidentalista del mundo ${ }^{14}$.

Como bien denunciaba en una de sus entrevistas, Sherkat pide acabar con los estereotipos, porque, al final, "ni en un lado ni en el otro se habla de mujeres pensadoras, filósofas o luchadoras" (Sherkat, 2008), lamenta, sólo de la sumisión de la mujer oriental y de la pérdida de valores de la occidental. El acabar con estas barreras, en muchos casos autoerigidas por las propias mujeres, resulta especialmente relevante para la consecución de la igualdad, tanto con respecto al hombre como a la mujer occidental.

\footnotetext{
${ }^{14}$ Como ejemplo de esta incomprensión, señalamos su intervención, el 16 de enero de 2008, en la Facultad de Filosofía y Letras de Cáceres. Allí participaba, junto a otra destacada activista, Azam Taleghani, en el Congreso Internacional Iridiscencias sobre países asiáticos y musulmanes, organizado por la catedrática de Historia Contemporánea y reconocida iranóloga, $\mathrm{M}^{\mathrm{a}}$ Jesús Merinero. El desconocimiento de las coordenadas socio-culturales y religiosas del Irán contemporáneo, así como la pervivencia de los clichés y estereotipos en torno a la situación de la mujer en el Islam, derivaron en que la intervención de Sherkat, centrada en una relectura de los principios religiosos que concedían un estatus igualitario a la mujer, fuera entendida por un sector del público asistente como una defensa de la subordinación de la mujer a las imposiciones religiosas.
} 
Dejando a un lado la censura y las incomprensiones mutuas, el discurso de Sherkat es claro y se basa una lectura feminista del Islam para exigir una reforma del pensamiento religioso. Así, en su primer editorial como directora de Zanan, reclamaba la reinterpretación del Corán para legitimar la igualdad entre sexos: "El Corán reconoce la igualdad entre hombre y mujer, por lo que el problema radica en la interpretación que se hace del texto y las leyes" (Sherkat, 2008).

De forma que, lo que plantea Sherkat, al igual que Taleghani y otras tantas feministas islámicas, entre ellas Asma Barlas (Barlas, 2008: 43-60), es la hermenéutica coránica como medio para que la mujer reivindique su liberación de patrones de sumisión e inferioridad. En este sentido, las iraníes afirman que "El Islam es un arma de cambio para las mujeres" (Sherkat, 2008a), criticando la educación en la que tradicionalmente se forman, en virtud de la cual asumen su inferioridad con respecto al hombre (Najmabadi, 1998: 91-125):

"Lo que nosotras criticamos, sobre todo es a quienes en nombre del Islam establecen discriminación con las mujeres. Personalmente, creo que Dios, creando al hombre y a la mujer no ha querido hacer discriminación entre ellos. Por desgracia muchos hombres creen que las mujeres son por naturaleza inferiores. Pero también muchas mujeres lo piensan porque se han educado en esta idea. Ellas son aún más víctimas que las otras porque están totalmente alienadas. Esta desigualdad es la raíz de todo el mal” (Merinero, 2004: 88).

En cuanto a su implicación política, en la campaña electoral de 1997, Sherkat inició una movilización masiva de sus lectoras y, por ende, del electorado femenino, en torno a Jatami y a los candidatos moderados-reformistas. De hecho, se muestra bastante crítica con Almadineyad, cuyas medidas restrictivas han vuelto a afectar al colectivo: "Desde el comienzo del gobierno de Mamad Ahmadineyad se ha recalcado que la tarea más importante de la mujer es ser ama de casa y cuidar a los hijos" (Sherkat, 2008b).

La labor al frente de Zanan ha sido reconocida con la concesión de distintos galardones. Entre ellos, el Premio al Coraje en el Periodismo en su edición de 2005, convocado por la Fundación de Medios de Comunicación Internacionales sobre la Mujer, y el Premio Louis M. Lyons a la conciencia e integridad periodística en la edición de ese mismo año, concedido por la Fundación Nieman de Periodismo de Harvard. En 2007, la Asociación Iraní de Periodistas la designaba una de las cinco periodistas del año. Un reconocimiento este último, que habría contribuido a alcanzar mayor repercusión y, en consecuencia, a que las autoridades se apresuraran a clausurar definitivamente la revista en sus dos formatos.

Sin renunciar a los principios islámicos ni renegar de las conquistas y éxitos de la Revolución, Sherkat ha experimentado el paso de un periodismo femenino, como el de Zan-e $R u z$ al periodismo feminista de Zanan. Año tras año, a través de sus páginas no ha dudado en reclamar una adaptación de los principios religiosos a las necesidades actuales, comenzando por dotar a la mujer iraní, motor del cambio y de las transformaciones sociales el país, de un estatus igualitario al del hombre.

Por todo ello, Sherkat y su revista constituyen un nexo de unión entre el reformismo islámico y las corrientes laicas, con un planteamiento que busca conseguir la libertad de 
derechos para las mujeres en el seno de la República Islámica que ella misma ayudó a levantar. Este enlace ha sido derribado por la censura estatal, pero sus cimientos se mantienen intactos y su legado puede percibirse en otros medios de comunicación iraníes que continúan luchando por sobrevivir.

\section{Conclusiones}

Testimonios y trayectorias como los de Sherkat, junto a los de otras tantas mujeres que hemos mencionado a lo largo de estas líneas, contribuyen a combatir la visión monolítica e inmovilista que tenemos de Irán y de sus mujeres.

La lucha de Sherkat y sus compañeras ha conseguido romper con muchos estereotipos y ha demostrado que las mujeres iraníes quieren, saben, y pueden defender sus derechos como muchas otras mujeres en el mundo. Sus reivindicaciones se basan en tres puntos esenciales: el cumplimiento de la Constitución y de los tratados internacionales concernientes a la igualdad de género; el libre ejercicio de un ijtihad que acomode las fuentes religiosas a las necesidades sociales del momento; y la adopción de un estatus político, jurídico y familiar de la mujer iraní en consonancia con los dos principios anteriores. Se trata de tres líneas de actuación estrechamente vinculadas con el proceso de democratización del país, en el que están inmersos todos los actores sociales agrupados en torno a partidos moderados-reformistas, asociaciones de derechos humanos y movimientos de mujeres.

En toda esta labor realizada, la contribución de Zanan ha sido especialmente destacable, no sólo por abrir sus páginas a todas las tendencias que coexisten en el movimiento, sino por actuar durante años como elemento unificador a la par que portavoz de las demandas de un colectivo muy heterogéneo que, a pesar de todos los obstáculos impuestos -incluido el propio cierre de la revista-, es capaz de sobreponerse y continuar luchando por sus derechos.

Es de desear que el inconformismo que siempre ha caracterizado a una joven y comprometida sociedad iraní continúe en este camino, el de los valores democráticos, y pueda imponerse, tanto al ultra-conservadurismo de las elites político-religiosas, como a los prejuicios occidentales, aún vigentes. 


\section{BIBLIOGRAFÍA}

- Amnesty International (2007): "Amnesty International concerned at continuing harassment of journalists and women's rights activists", [en línea] Disponible en: http://web.amnesty.org/library/Index/ESLMDE130152007 [30-11-2011].

- Anónimo (1998): "Rafsanjani's daughter cleared". En BBC News, 7 de diciembre de 1998, [en línea] Disponible en: http://news.bbc.co.uk/2/hi/middle_east/229749.stm [12-12-2011].

- Ardalán, Parvin, (2007): "Parvin Ardalan Olof Palme Prize Winner speaking”, 6 de marzo, [en línea] Disponible en: http://www.youtube.com/watch?v=hH-MXyv2Y_I [11-10-2011].

- Barlas, Amina (2008): “La hermeneútica coránica y la liberación de la mujer”. En VVAA: (eds.), La emergencia del feminismo islámico. Selección de ponencias del Primer y Segundo Congreso Internacional de Feminismo Islámico, Barcelona: Oozebap, pp. 43-60.

- Daragahi, Haideh (2010): “Against gender Apartheid. Interview with Parvin Ardalan”. En Independent World Report, February, 2010, [en línea] Disponible en: http://www.independentworldreport.com/2010/ 02/against-gender-apartheid/ [11-12-2011].

- Ebadi, Shirin (2003): “The Nobel Peace Prize. Nobel Lecture”, 12 de diciembre, [en línea] Disponible en: http://nobelprize.org/nobel_prizes/peace/laureates/2003/ebadi-lecture-e.html [12-12-2011].

(2009): “Treinta años de la Revolución Islámica”, [Conferencia], Universidad de Sevilla, 24-06-2009.

- Esfandiari, Golnaz (2009): "Women Call For Gender Equality Ahead Of Iran's Presidential Vote". En Payvand Iran News, 5 de marzo de 2009, [en línea] Disponible en: http://www.payvand.com/news/ 09/may/1014.html [12-12-2011].

- Haddad, Emmanuel (2009): "Entretien avec Shahla Sherkat", [en línea] Disponible en: http://www.fluctuat.net/6737-Zanan-journalisme-feministe-en-Iran [12-12-2011].

- IFEX (Intercambio Internacional por la Libertad de Expresión) (2008): "Cuatro ciberfeministas condenadas a seis meses de cárcel", 5 de septiembre de 2008, [en línea] Disponible en: http://www.ifex.org/gender_and_sexuality/2008/09/05/six_month_prison_sentences_handed/es/[12-12-2011].

- Khatami (1998): “Khatami supports press freedom”. En BBC News, 25 de noviembre de 1998, [en línea] Disponible en: http://news.bbc.co.uk/2/hi/middle_east/221860.stm [12-12-2011].

- IWMF (International Women's Media Foundation) (2005): “A Feminist Among Iran's Fundamentalists: Shahla Sherkat risks her freedom to cover women's issues". En IWMF Wire, Vol. 15, $\mathrm{n}^{\text {o }}$ 2, pp. 4 - 9, [en línea] Disponible en: http://www.iiav.nl/ezines/email/IWMFWire/2005/ No2.pdf [12-12-2011].

- IHRAG (Iranian Human Rights Activist Groups in EU and North America) (2006): "July 2006 Report: Evidence about the widespread, planned and systematic violation of Human Rights in Iran", [en línea] Disponible en: http://www.iransos.com/Menschenrechtsverlezung/July06.htm [11-10-2011].

- Karimian, Ramin y Bahrampour, Sha'banali (1999): “Iranian Press Update”. En Middle East Report Online (MIRO), vol. 29, $\mathrm{n}^{\circ}$ 212, pp. 38-39, [en línea] Disponible en: http://www.merip.org/mer/ mer212/212_press-update.html [12-12-2011].

- Kristianasen, Wendy (2004): "Hard-won change in Iran and Morocco". En Le Monde Diplomatique, edición inglesa de abril de 2004, [en línea] Disponible en: http://www.hartfordhwp.com/archives/ 27b/086.html [12-12-2011].

- Merinero, Ma Jesús (2001): Irán: hacia un desorden prometedor. Madrid: Los Libros de la Catarata. 
. (ed.) (2004): La República islámica de Irán: dinámicas sociopolíticas y relevo de las élites. Madrid: Los Libros de la Catarata.

- Mir-Hosseini, Ziba (1993): Marriage on trial: Islamic family law in Iran and Morocco Society and culture in the modern Middle East. Princeton: I.B.Tauris.

(ed.) (2000): Islam and gender: the religious debate in contemporary Iran. Princeton: I.B.Tauris.

. (2006): “Is Time on Iranian Women Protesters' Side?". En Middle East Report Online, $\mathrm{n}^{\circ}$ 16, [en línea] Disponible en: http://www.merip.org/mero/mero061606.html [12-12-2011].

- Moghadam, Valentine (2002): "Islamic Feminism and Its Discontents: Toward a Resolution of the Debate". En Journal of Women in Culture and Society, vol. 27, nº 4, pp. 1135-1171.

- Najmabadi, Afsaneh (1998): “Crafting and Educated Housewife in Iran”. En Lila Abu-Lughod (ed.): Remaking women: feminism and modernity in the Middle East. Princeton University Press, pp. 91-125.

(1998a): "Feminism in an Islamic Republic: 'Years of Hardship, Years of Growth". En Yvonne Yazbeck y John L. Esposito (eds.): Islam, Gender, and Social Change. New York: Oxford University Press, pp. 59-84.

- Paidar, Parvin (2001): "Gender and Democracy: the Encounter between Feminism and Reformism in Contemporary Iran". En United Nations Research Institute for Social Development, Democracy, Governance and Human Rights Programme Paper, $\mathrm{n}^{\circ}$ 6, [en línea] Disponible en: http://www.onlinewomeninpolitics.org/beijing12/paidar.pdf [11-12-2011].

- RSF (Reporteros Sin Fronteras) (2008): “Alerta: Cuatro ciberfeministas condenadas a seis meses de cárcel”, 5 de septiembre de 2008, [en línea] Disponible en: http://www.ifex.org/gender_and_sexuality/2008/09/05/six_month_prison_sentences_handed/es/ [12-122011].

- Ruiz de Almodóvar, Caridad (2006): "Hacia un nuevo concepto de familia: principales cambios del nuevo código marroquí de la familia". En Carmelo Pérez Beltrán (ed.): Sociedad civil, derechos humanos y democrática en Marruecos. Granada: Universidad de Granada, pp. 353-367.

- Sherkaloo, Mahsa (2005): "Iranian Women Take On the Constitution", [en línea] Disponible en: http://www.wluml.org/node/2370 [10-10-2011].

- Sherkat, Shahla (1992): "Editorial”. En: Zanan, n 1, febrero, pp. 2-3.

. (2008): "El Corán no es el problema. Dos mujeres iranís reclaman la igualdad de sexos en el mundo musulmán". En El periódico de Extremadura, 16 de enero, p. 1.

(2008a): "El Islam es un arma de cambio para las mujeres". En Público, 18 de enero, [en línea] Disponible en: http://www.publico.es/internacional/38710/el-islam-es-un-arma-de-cambiopara-las-mujeres [12-12-2011].

(2008b): "Entrevista a Shahla Sherkat", 16 de enero, [en línea] Disponible en: http://www.claudevolta.capellades.net/material/articles/shalah.htm [10-10-2011].

. (2009): “Telling the Stories of Iranian Women's Lives". En Nieman Foundation for Journalism Reports. Harvard University, [en línea] Disponible en: http://www.nieman.harvard.edu/reportsitem.aspx? id=101473 [12-12-2011].

- Tohidi, Nayereh (2008): “Zanan, Iran's Leading Women's Magazine, Shut Down by Government”. En Women's Learning Partnership for Rights, Development and Peace (WLP), 8 de febrero, [en línea] Disponible en: http://www.learningpartnership.org/advocacy/alerts/zanan0208 [10-10-2011].

- Van Den Abeele, Charlotte (s.d.): "Semblanza: Parvin Ardalan”, [en línea] Disponible en: http://www.1325mujerestejiendolapaz.org/otrsem_parvin.html [10-10-2011]. 